\title{
PENDAMPINGAN STRATEGI KUALITAS LAYANAN \\ TAMBAHAN (AUGMENTED PRODUCT) PADA USAHA IILA SALON
}

\author{
Tri Palupi Robustin \\ Jurusan Manajemen, STIE Widya Gama Lumajang \\ e-mail: tripalupirobustin@gmail.com
}

\begin{abstract}
The problem with this salon business is the lack of knowledge about optimal service strategies, especially to attract consumers to come back to the salon. Based on the background and problems, this community service activity aims to provide assistance to Iila Salon owners related to the quality of additional services (augmented products). Additional service quality strategy after sale in the form of giving away free hair cap (shampoo headgear) and providing free shampooing for customers who have come to the salon for treatments such as rebonding and smoothing. The strategy aims to make customers satisfied with the service and ultimately have an impact on loyalty. The results of the implementation of this community service activity are: (1) Survey of business locations so that information obtained Iila Salon place and approval of cooperation contracts with partners / owners of salons. (2) Interview with the owner of Iila Salon, information was obtained related to the history of the establishment of the business and the problems faced so that the community service team can provide solutions related to the problem. (3) Provide assistance in the form of rebonding drugs, hair stamps, shampoos and conditioners so that salon owners can later implement additional service quality strategies (augmented products) that have been taught by the community service team.
\end{abstract}

Keywords : Iila Salon, Augmented Product, Service Quality 


\section{PENDAHULUAN}

Usaha jasa salon merupakan bisnis yang dapat dijadikan bisnis jangka panjang, dikarenakan kebutuhan fisik untuk seorang wanita dibutuhkan, bahkan seorang pria pada beberapa tahun ini sudah mulai menunjukan kebutuhan tentang diri mereka. Hal ini dapat dijadikan sebagai peluang bisnis bagi para pendiri-pendiri salon yang ada di desa sekalipun. Salon merupakan ladang bisnis yang menguntungkan, mereka menganggap makin ke depan bisnis salon dan kecantikan semakin maju. Karena sekarang ini, salon sudah menjadi kebutuhan pokok yang harus dipenuhi sebagai tempat perawatan dan kecantikan tubuh.

antara lain:

Beberapa strategi supaya usaha jasa salon dapat memiliki banyak pelanggan

1. Lokasi usaha yang tepat

lokasi yang strategis agar usaha salon kecantikan dapat dilihat dan memiliki akses yang mudah untuk didatangi. Carilah lokasi kawasan umum seperti perkantoran, kampus, dan pusat perbelanjaan.

2. Pelayanan yang baik

Pelanggan sangat menyukai pelayanan yang baik, meskipun terbilang sederhana, pelayanan tidak bisa dianggap remeh. Usaha salon kecantikan tidak akan berjalan dengan baik jika pelayanan yang berikan tidak baik., karena jenis usaha ini termasuk dalam bidang jasa.

3. Berikan promosi yang menarik

Promosi menarik seperti harga diskon, untuk bentuk perawatan tertentu agar tidak mengalami kerugian. Dengan menerapkan promosi seperti diskon, layanan tambahan, maka pelanggan anda akan semakin tertarik.

4. Perbanyak fasilitas

Strategi lainnya adalah dengan cara memperbanyak fasilitas. Tawarkan pelanggan fasilitas lain seperti pijat, spa, lulur, bahkan pelatihan kecantikan. (https://goukm.id/usaha-salon-kecantikan)

Menurut Kotler (2002:83) definisi pelayanan adalah setiap tindakan atau kegiatan yang dapat ditawarkan oleh suatu pihak kepada pihak lain, yang pada dasarnya tidak berwujud dan tidak mengakibatkan kepemilikan apapun. Produksinya dapat dikaitkan atau tidak dikaitkan pada satu produk fisik. Pelayanan merupakan perilaku produsen dalam rangka memenuhi kebutuhan dan keinginan konsumen demi tercapainya kepuasan pada konsumen itu sendiri. Kotler juga mengatakan bahwa perilaku tersebut dapat terjadi pada saat, sebelum dan sesudah terjadinya transaksi. Pada umumnya pelayanan yang bertaraf tinggi akan menghasilkan kepuasan yang tinggi serta pembelian ulang yang lebih sering. 
Menurut Kotler dan Keller (2008:53), tingkatan produk sesuai dengan nilai tambahnya di bagi kedalam beberapa tingkatan yaitu:

a. Manfaat inti (Core benefit), merupakan jasa atau manfaat dasar yang sesungguhnya dibeli pelanggan.

b. Produk dasar (basic product), pemasar harus mengubah manfaat inti menjadi produk dasar.

c. Produk yang diharapan (Expected product), suatu set atribut dan kondisi yang biasanya diharapkan dan disetujui pembeli ketika mereka membeli produk.

d. Produk tambahan (Augmented product), pemasar menyiapkan produk yang ditingkatkan yang memenuhi keinginan pelanggan itu melampaui harapan mereka.

e. Produk potensial (Potential product), mencakup semua peningkatan dan transformasi yang akhirnya akan dialami produk tersebut dimasa depan.

Augmented product (produk tambahan) adalah berbagai atribut produk yang dilengkapi atau ditambahi berbagai manfaat dan layanan, sehingga dapat memberikan tambahan kepuasan dan bisa dibedakan dengan produk pesaing (Hasan, 2009:275). Produk tambahan adalah barang atau jasa yang diberikan kepada konsumen (selama dan sesudah penjualan) menyertai penjualan produk utama. Produk tambahan dapat merupakan barang nyata atau jasa agar dapat lebih memuaskan konsumen. Menurut Hasan (2009:277) jenis produk tambahan di bagi menjadi dua, yaitu :

a. produk tambahan pada saat pembelian, yaitu produk yang diberikan pada saat transaksi penjualan berlangsung. Misalnya, dalam pembelian sepeda motor mio akan langsung mendapatkan produk tambahan dari produk inti, seperti helm, jaket, gantungan kunci, dan stiker.

b. produk tambahan setelah pembelian, yaitu produk atau pelayanan yang diberikan setelah transaksi penjualan selesai. Misalnya, dalam pembelian motor yamaha mio setelah pembelian akan mendapatkan produk atau jasa tambahan seperti, suku cadang atau spare part, servis gratis, ganti oli gratis, kupon undian, dan lain-lain.

Iila salon merupakan usaha yang bergerak di bidang jasa yang berdiri sekitar tahun 2010. Usaha ini milik seorang ibu rumah tangga bernama Ida Hayu Reni yang memiliki alamat di Desa Wringintelu Kecamatan Puger Kabupaten Jember. usaha iila salon ini melayani berbagai macam perawatan kecantikan misalnya rebonding, smoothing, toning, potong rambut, semir rambut, keriting bulu mata, eyelash, creambath, masker rambut, sambung rambut, catok vitamin. Pelanggan Iila salon banyak yang melakukan perawatan terutama rambut yaitu rebonding, smoothing, toning, dan catok vitamin. Permasalahan pada usaha salon ini adalah kurangnya pengetahuan tentang strategi pelayanan yang optimal, terutama untuk menarik minat konsumen supaya datang kembali ke salon.

Berdasarkan latar belakang dan permasalahan tersebut maka kegiatan pengabdian masyarakat ini bertujuan untuk memberikan pendampingan kepada pemilik 
Iila Salon terkait kualitas layanan tambahan (augmented product). Strategi kualitas layanan tambahan setelah penjualan dalam bentuk memberikan secara gratis hair cap (penutup kepala keramas) dan memberikan keramas gratis bagi pelanggan yang sudah datang ke salon untuk perawatan seperti rebonding dan smoothing. Strategi bertujuan supaya pelanggan merasa puas dengan layanan tamabahan tersebut dan akhirnya berdampak pada loyalitas.

\section{METODE}

Adapun langkah-langkah kegiatan pengabdian ini adalah sebagai berikut:

1. Survei lokasi Iila Salon dan tanda tangan kontrak kerja sama dengan pemilik usaha.

2. Wawancara dengan pemilik Iila Salon terkait sejarah berdirinya usaha dan permasalahan yang dihadapi serta memberikan pendampingan solusi terkait permasalahan yang dihadapi tersebut.

3. Membelikan bantuan obat rebonding, hair cap, shampoo dan conditioner untuk menerapkan strategi kualitas layanan tambahan (augmented product).

\section{HASIL DAN PEMBAHASAN}

Hasil pelaksanaan kegiatan pengabdian masyarakat ini adalah:

1. Survei lokasi usaha sehigga diperoleh informasi tempat Iila Salon dan persetujuan kontrak kerja sama dengan mitra/pemilik salon.

2. Wawancara dengan pemilik Iila Salon maka diperoleh informasi terkait sejarah berdirinya usaha dan permasalahan yang dihadapi sehingga tim pengabdian masyarakat bisa memberikan solusi terkait masalah tersebut.

3. Memberikan bantuan berupa obat rebonding, hair cap, shampoo dan conditioner sehingga pemilik salon nantinya dapat menerapkan strategi kualitas layanan tambahan (augmented product) yang sudah di ajarkan oleh tim pengabdian masyarakat.

Proses kegiatan pengabdian masyarakat diuraikan sebagai berikut:

1. Kegiatan pertama, yaitu pada tanggal 11 Februari 2021 mendatangi lokasi Iila Salon untuk melakukan survei lokasi dan tanda tangan surat pernyataan kerja sama dengan mitra. Kegiatan ini menghasilkan informasi terkait di mana lokasi usaha dan kesediaan pemilik salon untuk kerja sama dalam kegiatan pengabdian masyarakat, seperti yang terlihat pada Gambar 1. 


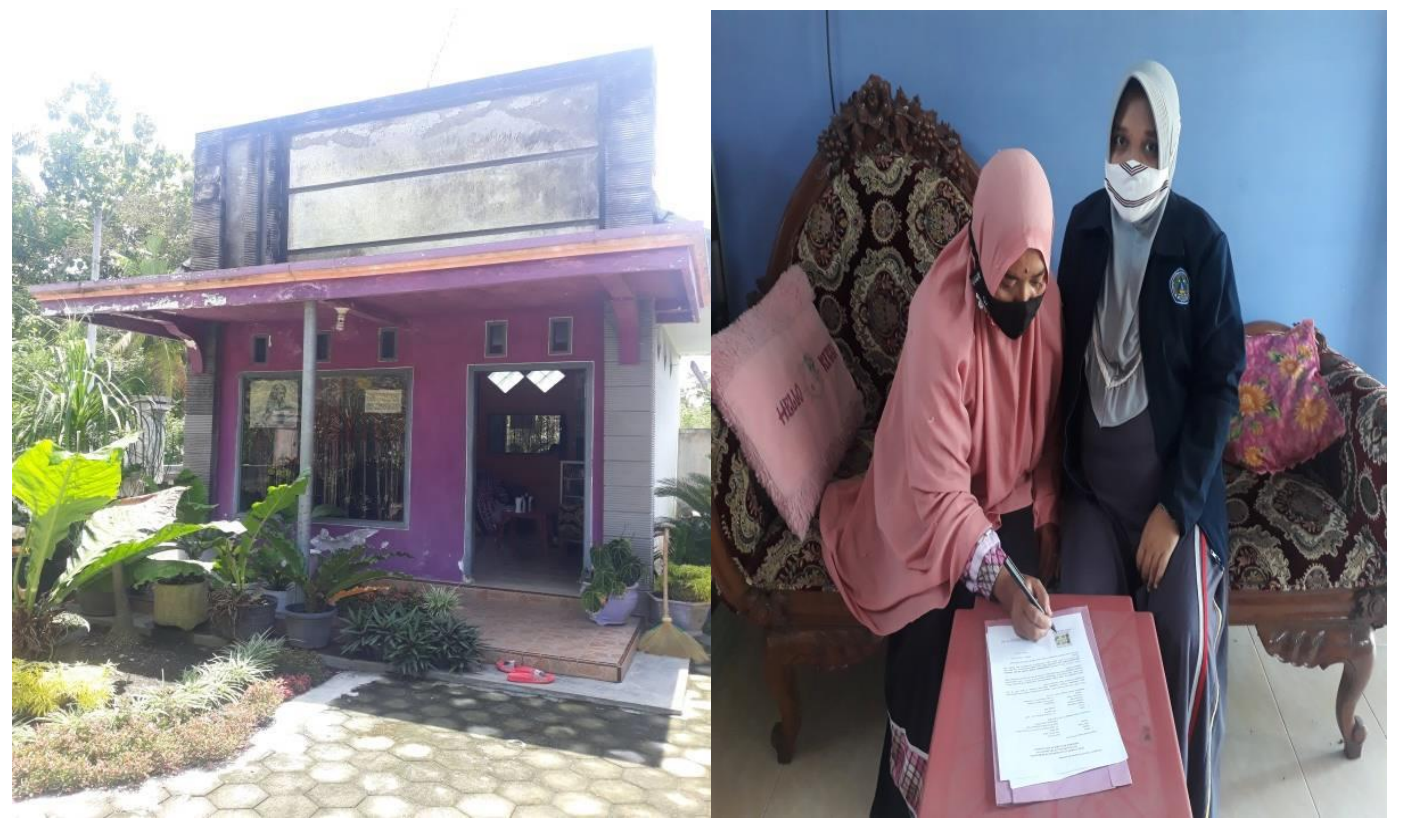

Gambar 1. Kegiatan Survei lokasi dan tanda tangan kontrak kerja sama Sumber: Penulis, 2021

2. Kegiatan kedua, yaitu pada tanggal 12 Februari 2021 wawancara terkait permasalahan mitra dan memberikan pendampingan solusi terhadap permasalahan mitra pengabdian sehingga diperoleh informasi terkait sejarah berdirinya usaha dan pemilik salon mendapat pengetahuan tentang kualitas layanan tambahan yang diberikan kepada pelanggan salon, seperti yang terlihat pada Gambar 2. 
Jurnal Pengabdian Masyarakat (JPM), Vol.1 No.2, Agustus 2021 hlm.46-52

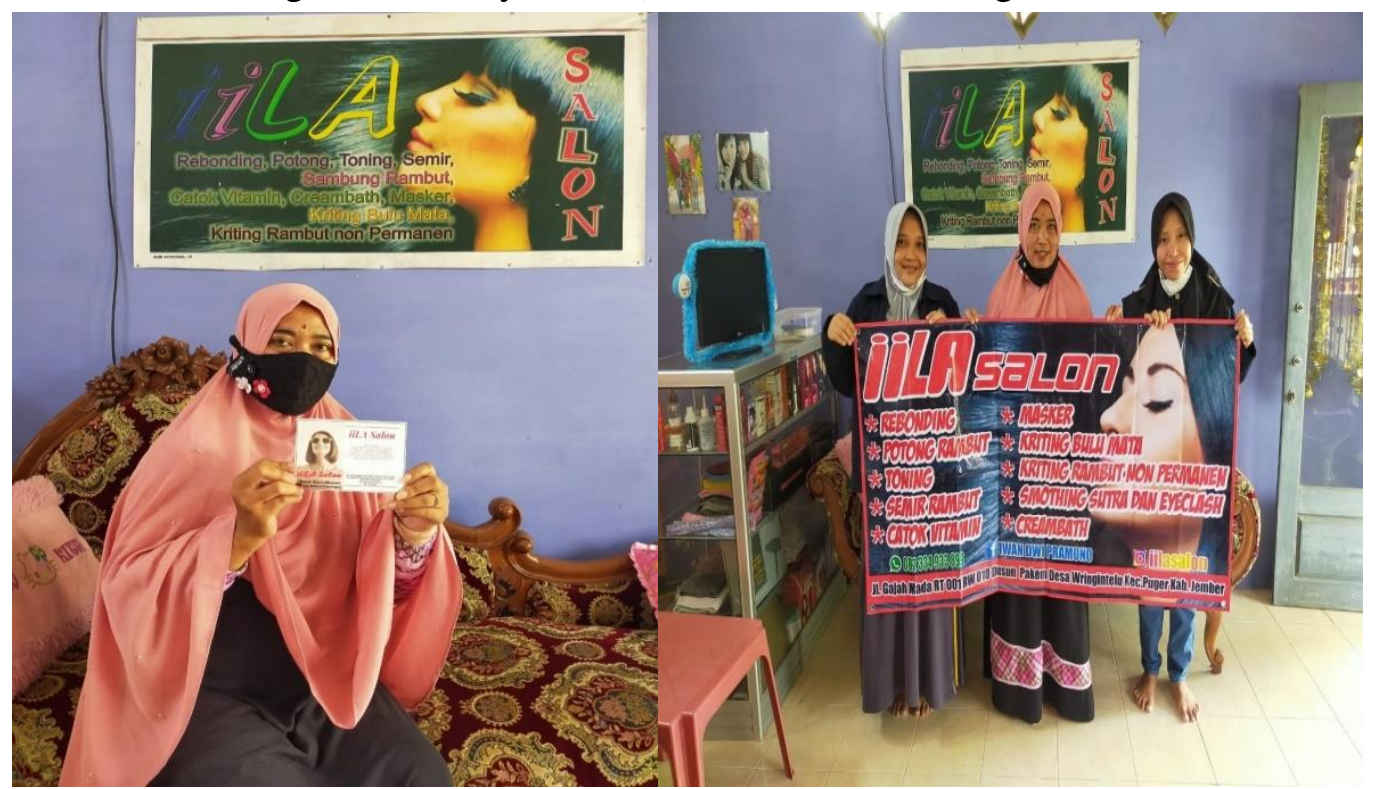

Gambar 5.2. Kegiatan wawancara dan pendampingan solusi

Sumber: Penulis, 2021

3. Kegiatan ketiga, yaitu pada tanggal 13 Februari 2021 Memberikan bantuan Obat Rebonding, hair cap, shampoo dan conditioner yang nantinya dapat digunakan mitra untuk memberikan layanan tambahan setelah pelanggan melakukan perawatan rambut, seperti terlihat pada gambar 3 .

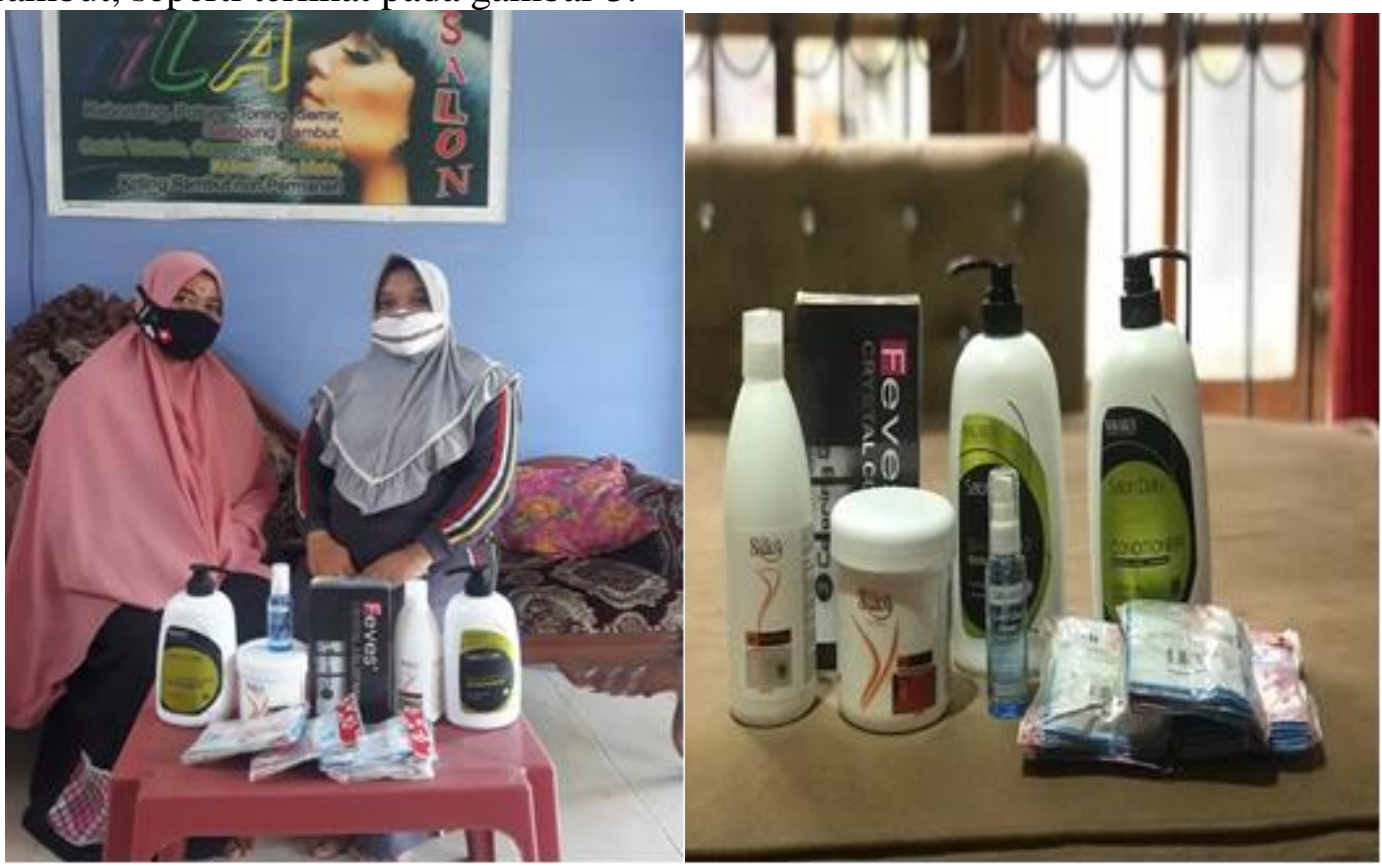

Gambar 3. Memberikan bantuan kepada mitra pengabdian Sumber: Penulis, 2021 


\section{KESIMPULAN}

Berdasarkan hasil pelaksanaan pengabdian kepada masyarakat yang telah dilakukan, dapat ditarik beberapa kesimpulan sebagai berikut:

1. Usaha Iila Salon merupakan usaha kecil yang bergerak di bidang jasa yang memiliki kendala usaha dalam strategi layanan tambahan (augmented product).

2. Pengabdian masyarakat ini memberikan pendampingan dalam hal strategi kualitas layanan tambahan (augmented product). Tujuan memberikan kualitas layanan tambahan setelah penjualan jasa adalah untuk menciptakan kepuasan dan loyalitas konsumen, karena usaha salon kecantikan saat ini sedang tumbuh banyak baik di perkotaan maupun di pedesaan. Kegiatan pengabdian masyarakat ini juga memberikan bantuan obat rebonding, hair cap, shampoo dan conditioner yang dapat digunakan pemilik salon untuk menerapkan strategi kualitas layanan tambahan setelah penjualan.

\section{DAFTAR PUSTAKA}

Hasan, Ali. 2009. Marketing, Edisi Baru. Yogyakarta : Media Pressindo.

Kotler, P. 2002. Manajemen Pemasaran, jilid 1, edisi milenium. Jakarta: Prehallindo.

Kotler, F., \& Keller, K. (2008). Marketing-Menedzhment [MarketingManagement]. Saint-Petersburg: Piter.

https://goukm.id/usaha-salon-kecantikan 